\title{
Rationalizing Health Personnel Financing Schemes for Evidence-informed Policy Reforms: Policy Analysis
}

\author{
Hilton Y. Lam, MHA, PhD, 1,2 Katrina Loren R. Rey, MD, 1,2 \\ Ma-Ann M. Zarsuelo, RND, MSc, ${ }^{1,2}$ Ma. Esmeralda C. Silva, MPAf, MSPPM, PhD,1,3 \\ Michael Antonio F. Mendoza, DDM, MA ${ }^{1,4}$ and Carmencita D. Padilla, MD, MAHPS 5 \\ ${ }^{1}$ University of the Philippines Manila Health Policy Development Hub \\ ${ }^{2}$ Institute of Health Policy and Development Studies, National Institutes of Health, University of the Philippines Manila \\ ${ }^{3}$ College of Public Health, University of the Philippines Manila \\ ${ }^{4}$ College of Dentistry, University of the Philippines Manila \\ ${ }^{5}$ University of the Philippines Manila
}

\begin{abstract}
Background. The Universal Health Care Law seeks to optimize financing of personnel costs without compromising quality and equitable health care among the health care facilities. This position statement aimed to identify strategies and policy recommendations for the cost-effective financing of health personnel in public healthcare facilities.

Methods. A systematic review of literature was done to generate policy brief and key points for roundtable discussion in collaboration with the Department of Health (DOH). The discussion was guided by the three health financing options of DOH: (a) retain Personnel Services (PS) as DOH budget but shift Maintenance and Other Operating Expenses (MOOE) to PhilHealth; (b) shift PS and MOOE to PhilHealth, and (c) rationalize part-time status in government hospitals.

Results. The pros and cons of financing options were cross-examined. In Option 1, physicians in government hospitals would receive fixed salaries from DOH / Local Government Units. In Option 2, there would be a monopsony between PhilHealth and provincial power. Payment will be performance-driven, and balance billing will be eliminated. Option 3 would be a set up of retaining part-time positions for physicians.

Conclusion and Recommendation. Participants deduced that for Option 1, provision of salary augmentation sources and ensuring adequate plantilla items and level of remuneration in government hospitals should be considered, in order to sufficiently compete with physicians' income from private practice. For Option 2, the PhilHealth reimbursement system should ensure timely reimbursement so as not to subject care providers to financial instabilities. For Option 3, rationalizing part-time status should be flexible and can be applied regardless of how physicians are paid, as this would incentivize caregivers to work harder and smarter.
\end{abstract}

Key Words: physicians, reimbursement mechanism, healthcare financing, universal health insurance

\section{INTRODUCTION}

Corresponding author: Ma-Ann M. Zarsuelo, RND, MSc UP Manila Health Policy Development Hub

National Institutes of Health

University of the Philippines Manila

623 Pedro Gil St., Ermita, Manila 1000, Philippines

Email:mmzarsuelo@up.edu.ph
Republic Act 11223, otherwise known as Universal Health Care (UHC) Law, seeks to initiate reforms in the health care system for the provision of accessible and comprehensive health coverage for all Filipinos across the spectrum of health promotion, disease prevention, curative, rehabilitative, and palliative health services. The aim is for health care to be cost-effective without increasing financial burden, especially for vulnerable populations. The World Bank, the Department of Health (DOH), and Philippine Health Insurance Corporation (PHIC or PhilHealth) estimated a total of $\mathrm{PhP} 408.6$ billion or USD 8.5 billion would be needed to expand UHC effectively in the period 
2012-2016. ${ }^{1}$ This translates to 3.6\% of the Philippine Gross Domestic Product (GDP). To streamline financing, the UHC Law seeks to optimize financing personnel costs while providing quality and equitable health care. Major stakeholders were convened in a roundtable discussion aimed to identify strategies to minimize duplication of personnel cost in public facilities.

The Universal Health Care Law is expected to bring reforms by re-centralizing health service management at the provincial level for better accountability and a more responsive health system. Sufficient and qualified human resources for health (HRH) are vital in achieving universal health coverage. ${ }^{2}$ Health human resource development (HHRD) involves the utilization of human resources for health planning, production, and management. This emphasizes the importance of sufficient supply and retention of health care providers nationwide. ${ }^{3}$

In the Philippines, there is a persistent challenge of the maldistribution of health workers, with the majority serving urban areas leaving a significant deficit in rural and remote areas. ${ }^{2}$ Several strategies have been implemented to address this. The University of the Philippines Manila College of Medicine (UPCM) started the Regionalization Program in 1985, which aims to address the inequitable distribution of physicians in the Philippines. In 2005, this was changed into a social contract for the student to serve his/her region of residence for the number of years equivalent to his/her medical education. ${ }^{4}$ In addition, the $\mathrm{DOH}$ deploys human health resources to complement existing health professionals in the Local Government Units (LGUs). ${ }^{3}$ In 1993, after identifying 271 municipalities without physicians, the Doctors to the Barrio (DTTB) Program was launched. ${ }^{5}$ Reported difficulties during their service include inadequate LGU support, politics, and areas prone to armed conflicts. ${ }^{3}$

At the other end of ensuring quality health care, there is also a need to improve the demand side for better accessibility and utilization of health services, especially among the poor. Demand-side financing (DSF) places the purchasing power and choice of a health provider to the people, and this strategy is seen as a means to improve service utilization. ${ }^{6}$ There is a direct relationship observed in DSF between the subsidy, its objective, and the target beneficiary. It can be consumer-led through vouchers, cash transfers, tax rebates, or provider-led through capitation payment or referral vouchers which can be given either before or after utilization of service.

With the challenges in both the supply and demand side of the health service, the awaited change of health system landscape through the UHC Law is hoped to redress these issues. As a macro-policy law introduced into an existing health system, evidence-informed policy development of its operationalization will provide an empirical basis with minimal bias in its implementation. Thus, the UP Manila Health Policy Development Hub (UPM HDPH), as the research agency, together with the Department of Health $(\mathrm{DOH})$, as the primary agency conducted research and a series of a multi-stakeholder roundtable discussions to generate scientific, legal, and expert evidence for the Implementing Rules and Regulations of the UHC Law. Upon the deliberation of the primary agency, one of the identified priority topics is financing health personnel. One of the main discussion points delved on the identified financing options of the $\mathrm{DOH}$ that needs further evidence: Option 1: Retain Personnel Services (PS) as DOH budget but shift Maintenance and Other Operating Expenses (MOOE) to PhilHealth; Option 2: Shift PS and MOOE to PhilHealth; and Option 3: Rationalize part-time status in government hospitals.

\section{METHODS}

Qualitative research was conducted, which utilized a systematic the review of literature and thematic analysis of the policy roundtable discussion. The flow of research inputs from review of literature to the crafting of the position statement is presented.

\section{Pre-work research}

To generate scientific and legal evidence for the policy issue, a systematic review of literature was conducted. This was utilized in crafting the policy brief and other key points for discussion during the policy roundtable discussion. The review of literature focused on the inefficiencies experienced in the current health financing scheme for health personnel and review of local and international experience with various health financing scenarios.

An electronic search of articles using PubMed was done to answer questions related to minimizing duplication in financing personnel cost. The keywords used were "Physicians"[MeSH] AND "Reimbursement Mechanisms"[MeSH] AND Salary, which generated 145 articles. Articles were screened by title, relevance, and abstract, respectively. To pool broader related references, a Google search was conducted using the above keywords. In total, 40 full-text records were included in the review (Figure 1).

\section{Review of Literature}

\section{Inefficiencies in the current scheme of financing health personnel}

A review of demand-side strategies for Universal Health Coverage by Bonilla-Chacin and Rathe (2018) revealed that in many countries, there was a separation between financing and provision. This split was justified by the need to secure efficiency gains, with the idea of fostering strategic purchasing. However, despite the efforts, the purchaserprovider split remained incomplete. National government continued to shoulder most costs, which usually include payroll through line-item budgets. ${ }^{7}$

In the Philippines, the purchaser-provider split remained incomplete as well. PhilHealth financed resources through 


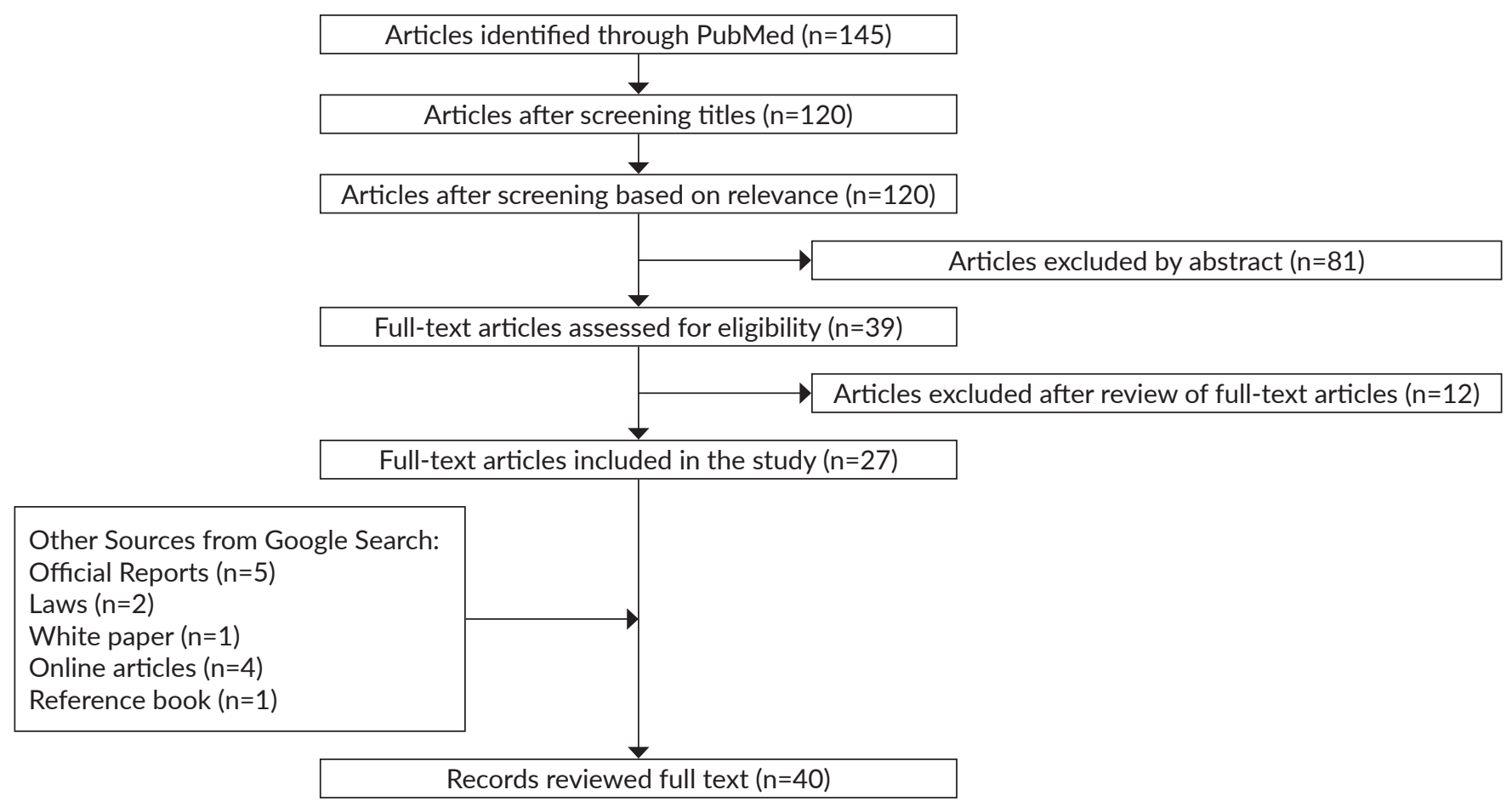

Figure 1. PRISMA diagram of article search.

the demand-side scheme. However providers were not held accountable for their performance. Another problem was that PhilHealth does not pay many public facility physicians directly, and instead remit their reimbursements to the LGUs which own the hospitals that these public physicians work in, with the rationale that these are already paid through their LGU line-item budgets. ${ }^{8}$

Since the Devolution, the Department of Health had difficulty in obtaining timely access to data from health providers both from the LGU and private sectors. Hence, there was difficulty in regularly monitoring program implementations. PhilHealth, as the public purchaser, could have a more direct impact on service delivery but failed to fully take advantage of this power. In the past, it was deemed that the accountability of PhilHealth to DOH, as an affiliated agency, was weak. An initiative to mitigate this was done through the balanced scorecard, which is a strategic planning and management system used to translate the organization's vision/mission into the operations. A lineitem budget system was also introduced into the $\mathrm{DOH}$ to allow channeling of funds from the Department of Budget and Management (DBM) to PhilHealth through DOH. This holds PhilHealth directly accountable to the performance of the sponsored program. ${ }^{5}$

\section{Local and international experience in different financing scenarios}

Table 1 shows the different pros and cons of each scenario based on local and international literature. The autonomy of health facilities and improved provider accountability on performance are valuable determinants in identifying potential mitigating measures under each option.

Currently, local health physicians are compensated through a combination of ways. In private practice, physicians charge fee-for-service except for patients covered by HMOs. For HMO-covered patients, physicians receive retrospective payment. Private physicians charge market-determined rates. Physician rates vary, and the gap between charges of primary care physicians compared to specialty care is widening which lead to a shortage of primary care physicians. ${ }^{18,19}$

Additionally, accredited PhilHealth physicians receive reimbursement based on the case rates of admitted patients. For the performance of a medical or surgical procedure, physicians are paid relative to the complexity of the procedure, which is seen in the assigned relative value unit (RVU). Correspondingly, the more difficult a procedure, the higher its RVU. ${ }^{11}$ However, there have been complaints about the determination of RVU, claiming that RVUs do not reflect discrepancies among subspecialties and do not reflect workload. ${ }^{20}$ Another claim is that RVU place a higher premium on procedural services compared to cognitive medical care. ${ }^{21}$

In the public health sector, physicians and health care professionals have paid salaries, which follow the stipulated rates from the Salary Standardization Law. ${ }^{14}$ The Magna Carta for Public Health Workers has provision for additional benefits depending on the basic salary, nature of work assignment, and the employer's ability to pay. They also receive PhilHealth reimbursements when they practice in PhilHealth-accredited facilities. 
Some physicians are unhappy with flat compensation because it does not account for a physician's subspecialty, experience, and work rendered. It also does not incentivize clinical productivity because it is expected as part of base pay. ${ }^{20}$ Fixed salaries may lead to underproductivity and under-provision of care. ${ }^{10,22}$ Salaried physicians had shorter consultation periods, and fewer follow-up consults. ${ }^{23,24}$ However, higher quality of service was seen among physicians who charge via fee-for-service compared to those with salaried compensation. ${ }^{25}$

Performance-based financing gives positive motivation for the quality of care improvement ${ }^{26}$ and physician productivity through full-time practice. ${ }^{27}$ It was viewed that pay-for-performance and financial incentives can improve health access and quality of service. ${ }^{25,28-30}$ However, financial incentives may lead to overutilization through overdiagnosis and overtreatment ${ }^{25,31}$ to avoid litigation or to increase income..$^{32}$ Physicians may focus on increasing their practice to maximize fee-for-service and incentives..$^{33-35}$ Some may also opt to provide unnecessarily more complex services and procedures for higher RVU and incentives. ${ }^{22}$

Changing the landscape of how physicians are compensated may be very unpopular with the profession and would face opposition. ${ }^{36}$ However it is vital to involve physicians in crafting compensation plans to adapt to the structure and values of various stakeholders involved. ${ }^{37-38}$ Some recommendations for value-based physician compensation were to: (i) relate contemplated changes in physician compensation to strategic and financial objectives, (ii) financial incentives should be focused on evidence-based measures that are credible and achievable, (iii) incentive measures and compensation plans should be understood before implementation and (iv) complete data transparency should be ensured. ${ }^{39}$ The quality and value of health care delivery should be the priority regardless of how physicians are paid. ${ }^{22}$

\section{Conduct of the policy roundtable discussion}

The UP Manila Health Policy Development Hub in collaboration with the Department of Health conducted the roundtable discussion (RTD) on the Universal Health Care (UHC) Act entitled, "Financing health services: Copayments and personnel cost" held on the $24^{\text {th }}$ of January, 2019 at Board Room, Philippine General Hospital. From the deliberation of UPM HPDH and DOH, objectives of the RTD were set, which generally aimed to identify services requiring copayments and minimize duplication in financing personnel cost in public health facilities. Specifically, the RTD aimed to answer the following questions:

1. Describe the extent of inefficiencies in the current set-up

2. Identify risks, mitigating measures, and possible steps for transition under each scenario:

Option 1: Retain Personnel Services (PS) as DOH budget but shift Maintenance and Other Operating Expenses (MOOE) to PhilHealth

Option 2: Shift PS and MOOE to PhilHealth

Table 1. Pros and Cons of DOH proposed options in financing personnel cost

$$
\text { PROs }
$$

Option 1: Retain Personnel Services (PS) as DOH/LGU budget but shift Maintenance and other operating expenses (MOOE) to National Health Insurance Program (NHIP)

- PhilHealth finances portions of the cost of health personnel services and part of the variable cost. ${ }^{7}$

- Physicians and health care professionals will have fixed salaries following Salary Standardization Law rates. ${ }^{8}$

- Based on the Magna Carta for Public Health Workers, additional benefits apply depending on the basic salary, nature of work assignment, and the employer's ability to pay.

- Governments are still responsible for infrastructure maintenance and investments for primary health care centers and local public health programs. ${ }^{7}$

- From the Canadian experience, cost control mechanisms through fixed budgets and pre-set physicians' fees, are negotiated between the ministry and provincial medical associations to eliminate the concept of extra billing. The government can distribute health practitioners of varied specialties, allocate new medical graduates, and disseminate diagnostic and surgical equipment. ${ }^{9}$

- Could be an effective method for recruitment and retention of physicians in under-supplied regions by providing stable and predictable income. ${ }^{10}$

- According to proponents of salary-based remuneration, there is quality of care improvement through an increase in disease prevention, health promotion, and professional collaboration. ${ }^{10}$

- Fixed payments lowered administrative costs for the health care system. ${ }^{10}$
- Difficulty for DOH and PhilHealth to monitor and evaluate the sponsored programs due to challenges in timely data accessibility and availability.

- With salaried physicians, there is a risk of possible societal opportunity cost from reduced productivity and under-provision of appropriate care. ${ }^{10,22}$ 
Financing Health Personnel

Table 1. Pros and Cons of DOH proposed options in financing personnel cost (continued)

- Reimbursements paid to public facilities can be other operating costs (except salaries) for the maintenance or improvement of service delivery and facilities in the public sector. ${ }^{11}$

- Facilities are accountable to PhilHealth for good service delivery and quality of care. ${ }^{12}$

- Single-payer insurers (i.e., PhilHealth) can bargain payment for physicians, hospital rates and purchase pharmaceuticals by bulk through virtue of monopsony. ${ }^{13}$ retained by the facility which may be used to settle

- PhilHealth needs more financial and human resources to function as an effective purchaser of health services. ${ }^{12}$

- Limited capacity of PhilHealth in monitoring compliance with policies given the need for timely and accurate data. ${ }^{12}$

- Long backlogs and delays in capitation by PhilHealth.

- Balance billing policy for health services that PhilHealth cannot fully cover, especially in private hospitals. This is due to the absence of regulation of the physician's fee (PF). ${ }^{12,14}$

As for the practice of HMOs, MOA with major surgical and medical specialty societies prescribe PFs of participating doctors. Government-paid doctors could explore this.

- Public facility health providers will have income solely from PhilHealth rather than both fixed salaries and PhilHealth.

- Lowering pay rates may lead to under-provision of care or total pull-out of services. ${ }^{13}$

- May give rise to the development of an alternative delivery system.

- Physicians may divide their time and give more attention to their private patients, compromising their care for public patients. Also, physicians would prefer a practice that would enable them to have long patient queues and a high volume of private patients. ${ }^{13}$

- Parallel markets where providers receive only revenue from out-of-pocket payments. Physicians who receive high income from out-of-pocket payments may not respond to payments offered by the public-sector. ${ }^{13}$

Option 3: Rationalize part-time status in government hospitals

- Part-time practice may work for primary care.

- Working part-time allows more flexible schedules allowing more work-life balance. ${ }^{15}$

- Part-time physicians may perform as well as full-time physicians in all aspects of primary care except visitbased continuity of care. ${ }^{15}$

- Part-time physicians are equally productive and more fulfilled with their work. ${ }^{16}$

- Part-time physicians have more liberty to pursue outside interests or commit to administrative or educational work. ${ }^{16}$
- Part-time practice may be harder to implement in some specialties especially in surgical practice since the responsibility of surgeons to the patients may be hard to hand over. ${ }^{17}$

- Issue arising from physician rounds and accepting emergency calls since the load for part-time and full-time physicians are not equivalent. ${ }^{16}$

- Patients may prefer full-time physicians, especially those placing a high value on continuity of care. ${ }^{16}$

- To what extent should benefits cover for part-time physicians?

- "Cost-neutral" approach- if the physician worked $60 \%$ of the full-time schedule, they should receive around $60 \%$ of the benefits for a full-time physician.

- Offer higher salaries to part-time physicians to compensate for the reduced benefits. Conversely, offer full benefits to off-set the reduction in salary from payroll tax. ${ }^{16}$

- May have a more complicated salary scheme due to additional considerations. Using the productivity-based formula, the following are the options:

- hourly wage, based on local averages;

- \% of full-time position's wage equivalent to \% of time worked;

- daily, weekly, or monthly payment depending on the pre-set number of days, hours or shifts worked;

- profitability-based payments computed as revenue less overhead;

- combination (i.e., fixed salary augmented by bonus depending on pure production, e.g., charges, encounters, RVUs, etc. compared to a target). ${ }^{16}$
Option 3: Rationalize part-time status in government hospitals.

3. Provide additional options as may be deemed necessary.

A total of 26 discussants from various national government agencies, local government units, private sector, hospital representatives, academe, professional societies, HMOs, and non-government organizations participated in the discussion.

In general, collective analysis of the strengths and weaknesses of different options in mitigating duplication of personnel cost was the locus of the discussion. The advantages and disadvantages of the three health personnel financing options identified by $\mathrm{DOH}$ as summarized in Table 1 was presented during the RTD for review and inputs of the stakeholders.

\section{Policy Analysis}

Thematic analysis of the RTD transcription was done using the discussion questions as the sub-themes. In citing insights of the participants in the position statement, their identities were not disclosed for confidentiality. Nevertheless, all participants were informed that the proceeding of the RTD would be published with their names in the 
Acknowledgment Section. To confirm consensus, the draft of the policy paper was circulated to the participants for inputs and approval, then reviewed by all the members of UPM HPDH before submitting to the Chancellor for review and approval. Both the policy discussion and review of literature were utilized in crafting the policy paper.

\section{RESULTS AND DISCUSSION}

The Universal Health Care Law is expected to bring reforms by re-centralizing health service management at the provincial level for better accountability and a responsive health system. With the current challenges in both the supply and demand side of the health service, the awaited change of health system landscape through the Act is hoped to redress these challenges.

In the current setting, physicians in government health facilities are salaried by $\mathrm{DOH}$ or Local Government Units. In addition, for PhilHealth accredited facilities, reimbursements are also received. Hence, there is a possible duplication in payment. The DOH is eyeing for three options deemed to bring forth the needed policy reforms for costefficient health financing. Arguments for and against the different scenarios were presented in the discussion.

\section{Inefficiencies abound in the current set-up}

During the discussion, ground experiences on the current scenarios on provincial health systems were shared. One discussant reported that in one provincial hospital, a physician with plantilla item in a Level II hospital could earn as much as $\mathrm{PhP} 100,000$ per month from PhilHealth reimbursements on top of a fixed salary. On the other hand, contractual physicians would gain $\mathrm{PhP} 30,000$ to $\mathrm{PhP} 40,000$ per month from PhilHealth reimbursement shares. This could unintentionally have a downfall wherein physicians would opt to stay in higher-level hospitals, refusing deployment to infirmaries or municipal hospitals, where PhilHealth reimbursement is less.

An issue that was raised regarding the retention of the medical officer plantilla item at the municipality, while re-nationalizing to the provincial level is the fear that the personnel services cap would prevent the Provincial City Health Board from hiring doctors or health professionals, even if there will be more funds to pay for these doctors or health professionals. A review of the health professional to population ratio is warranted to secure evidence for the raising of this personnel services cap.

\section{Identifying risks, mitigating measures, and possible steps for transition in each scenario}

\section{Option 1: Retain PS as DOH / LGU budget but shift MOOE to NHIP}

There is a need to determine whether the perceived shift would affect personnel in rural health units and other non-hospital-based health workers. Also, the government teaching-training hospitals and district hospitals might have different dynamics in personnel salaries and MOOE, which might call for modified set-up.

In this option, physicians will receive fixed salaries from DOH / LGU and would not get PhilHealth reimbursement shares. However, with the current salary standardization, the salary for consultants and medical specialists in government hospitals cannot compete with what physicians earn in private practice. Hence, physicians may be inclined to transfer to private health facilities where they are allowed to have PhilHealth and HMOs capitation on top of their basic pay.

While it can be argued that the pooled funds from PhilHealth should not be considered as duplication of fees, but rather as augmentation, however, the intended salary augmentation will not be possible in Option 1, leaving the low basic salary as the sole source of professional fees. This may cause a problem in the retention and acquisition of health care workers and may worsen the emigration of skilled and experienced health professionals. Nevertheless, some specialists may still opt to serve in a government health facility due to non-monetary reasons, e.g., familial, personal passion, patriotism, others.

Another challenge is the lack of doctors in rural health units (RHU). Lack of serving physicians in the RHU pushes more patients to go to secondary and tertiary hospitals for health complaints that could have been managed earlier or more cost-efficiently in the RHUs.

\section{Option 2: Shift PS and MOOE to NHIP}

For Option 2, there will be a monopsony: PhilHealth and provincial power. This is the current setup among HMOs, which could be adopted by social insurance. The provincial service delivery network or the city service delivery network should be able to monitor their members that balance billing will not be allowed. Payment will be performance-driven and serve as the basis for incentives. Another suggestion is that, when physicians reach a specific target, then they can receive commission for additional services rendered. However, there is hesitancy in the operational efficiency of this option, since if health professionals solely depend on performancebased fees from PhilHealth, delayed reimbursements might expose them to financial instability.

Another barrier is political interference in delivering quality and accessible healthcare services. This can hamper the proper implementation of policies, failing to attain the target output. In the UHC Law, it is imperative to minimize or eliminate the politicized decision making, to have efficient health care delivery.

The provincial health board will be tasked to manage the special health fund. Based on the previous discussion on province-level integration, it was proposed that the governor will head the board and a steering committee comprised of representatives from each municipality and other sectors. This is stipulated in Section 19 of the Act stating that ".... 
Table 2. Summary of insights of RTD discussants on the advantages, disadvantages, and issues/problems arising from the DOH proposed options in financing health personnel

Option 1: Retain Personnel Services (PS) as DOH/LGU budget but shift Maintenance and other operating expenses (MOOE) to National Health Insurance Program (NHIP)
- Re-nationalizing to the provincial level through the Provincial / City Health Board can place a salary cap on physicians.
- Physicians will receive fixed salaries from DOH/ LGU and would not get PhilHealth reimbursement shares. The basic salary as the sole source of professional fees
- Some specialists may still opt to serve in a government health facility due to non- monetary reasons, e.g., familial, personal passion, patriotism, others.

- In the current salary standardization scheme, the salary for consultants and medical specialists in government hospitals cannot compete with what physicians earn in private practice.
- Personnel services cap may prevent the Provincial / City Health Board from hiring doctors or health professionals, even if there will be more funds to pay for these doctors or health professionals.

- It is unclear if the financing scheme would affect personnel in rural health units and other non-hospital-based health workers.

- Government teaching-training hospitals and district hospitals might have different dynamics in personnel salaries and MOOE, which might call for modified set-ups.

- Physicians may be inclined to transfer to private health facilities where they can have PhilHealth and HMOs capitation on top of their basic pay.

- The pooled funds from PhilHealth can be considered as augmentation of basic pay, not as duplication of fees.

- The emigration of skilled and experienced health professionals to private facilities may worsen.

- Despite available plantilla items, rural areas still lack doctors.
Option 2: Shift PS and MOOE to NHIP

- There will be a monopsony: PhilHealth and provincial power.

- The network should be able to monitor their members that balance billing is not practiced.

- Payment will be performancefor incentives. driven and serve as the basis
- If health professionals solely depend on performance-based fees from PhilHealth, delayed reimbursements might expose them to financial instability. quality and accessible healthcare services can hamper the proper implementation of policies.
- Political interference in delivering

- Physicians would opt to stay in higher level hospitals and may refuse deployment to the infirmary or municipal hospital, where PhilHealth reimbursement is less.

- It was suggested that when physicians reach a certain target, then they can receive a commission for additional services rendered.

- It is imperative to minimize or eliminate politicized decision making, to have efficient health care delivery.

- The operational definition of "a representative" to the Provincial or City Health Board should be clarified as to how many representatives will be included, whether it is one each municipality or one for the whole province.

\begin{tabular}{|c|c|c|}
\hline \multicolumn{3}{|c|}{ Option 3: Rationalize part-time status in government hospitals } \\
\hline $\begin{array}{l}\text { Better schedule flexibility and } \\
\text { more income opportunities for } \\
\text { health professionals. } \\
\text { - Part-time status for physicians } \\
\text { can be applied in either Option } \\
1 \text { or } 2 \text { scenarios, regardless of } \\
\text { how physicians are paid. }\end{array}$ & $\begin{array}{l}\text { - More physicians may prefer part-time } \\
\text { positions that result in difficulty in } \\
\text { employing full-time positions. } \\
\text { - May have more complicated salary } \\
\text { scheme and benefit coverage. } \\
\text { - Physicians might lean towards } \\
\text { greater prioritization for private } \\
\text { patients due to better compensation. }\end{array}$ & $\begin{array}{l}\text { - In some institutions, a full-time position is divided among } \\
\text { individual practitioners. The practice of part-time status } \\
\text { becomes more prevalent since medical specialists and allied } \\
\text { medical professionals who offer home care therapies receive } \\
\text { higher fees in private practice. } \\
\text { - Some physicians who are employed as full-time physicians } \\
\text { may perform less than part-time in terms of workload and } \\
\text { hours of work. The deliverables should be clearly stated for } \\
\text { part-time physicians. }\end{array}$ \\
\hline
\end{tabular}

municipalities and cities included in the province-wide and city-wide health systems shall be entitled to a representative in the Provincial or City Health Board." Some of the discussants were concerned about the operational definition of "a representative" and suggested that there needs to be a clarification as to how many representatives will be included, whether it is one each municipality or one for the whole province.

\section{Option 3: Rationalize part-time status in government hospitals}

It was reported during the discussion that though plantilla positions in government health facilities are available, they are not quickly filled up as some physicians prefer part-time positions. This is due to schedule flexibility and more income opportunities. It is also interesting to note that in some institutions, a full-time position is divided among individual practitioners. The practice of part-time status become prevalent since medical specialists and allied medical professionals who offer home care therapies receive higher fees in private practice.

On another note, there are instances when employed full-time physicians perform less than part-time in terms of workload and hours of work. This can be attributed to the gained security from tenured items in the government. To ensure quality service provision, the deliverables should be clearly stated for part-time physicians. 
As a public servant, patient welfare must always come first. However, if private practice is placed in the equation, physicians might lean towards greater prioritization for private patients due to higher compensation. Lastly, there was a consensus that rationalizing part-time status in health facilities should be flexible and can be applied in either Option 1 or 2 scenarios, regardless of how physicians are paid.

A summary of the insights from the discussants of the RTD, comparing the advantages, disadvantages, and issues/problems arising from the $\mathrm{DOH}$ proposed options in financing health personnel, is presented in Table 2.

\section{Additional options as may be deemed necessary}

To achieve cost-efficient health financing, another option in financing personnel cost is for the health professionals to have a fixed salary and still allow them to have augmentation from PhilHealth reimbursement up to a certain amount. Once this amount is reached, further augmentation can be restricted. This can incentivize the retention of health professionals in government health facilities while preventing the abandonment of charity or no balance billing (NBB) patients.

Another concern raised in the discussion is the "moonlighting" practice, which is becoming the preference of new medical graduates, rather than taking residency training. Moonlighting is defined as the extracurricular provision of medical services for remuneration outside the bounds of residency training programs. ${ }^{40} \mathrm{It}$ is strongly attributed to higher fees received. However, this arrangement lack continuity of patient care and compromises the quality of service.

\section{CONCLUSION AND RECOMMENDATIONS}

The UHC Act is expected to increase fundings for healthcare for the efficient provision of equitable quality health services and commodities. Examining all possible financing schemes with the best available evidence and experience will identify the mechanisms that would yield the best allocational efficiency. There is a consensus that each of the presented financing options requires actions on the current policy gaps. Further, the flexibility of terms among health personnel must be considered to augment salaries with other sources. Discussions revolved around impacts on the financial security of the health personnel while ensuring the provision of fair and quality services. To be able to shift the personnel salaries and MOOE from $\mathrm{DOH}$ to PhilHealth, there must be a critical analysis if the existing and projected PhilHealth financial and human resources would be sufficient to cover and manage all of these, respectively. Even though there are more resources allocated to fund the UHC, it is important to note the efficiency of fiscal sustainability. This means that allocation and technical efficiency must be improved, and primary care is strengthened.
Based on the review of literature and policy discussion, the following are recommended:

1. For the options to minimize duplication of personnel cost, there is a need to determine whether the perceived shift would affect personnel in rural health units and other non-hospital-based health workers. Also, government teaching-training hospitals and district hospitals might have different dynamics in personnel salaries and MOOE, which might call for modified set-ups.

2. There must be a clear operational definition of "a representative" and clarify how many representatives will be included in the provincial health board, as stipulated in Section 19 of the Act.

3. For Option 1, consider providing another source of salary augmentation for physicians. Also, ensure adequate plantilla items in LGU-maintained hospitals.

4. For Option 2, given that salaries solely depend on PhilHealth, it is imperative to fix PhilHealth reimbursement system for timely reimbursement.

5. Political interference in delivering quality and accessible healthcare services can hamper proper implementation of policies that may lead to failure in attaining the target output. In the UHC Act, it is imperative to minimize or eliminate politicized decision making, to have efficient health care delivery.

6. Part-time status schemes should be flexible, and can be applied to either Option 1 or 2 scenarios, regardless of how physicians are paid.

\section{Statement of Authorship}

All authors participated in data collection and analysis, and approved the final version submitted.

\section{Author Disclosure}

All authors declare no conflicts of interest.

\section{Funding Source} HPSR.

This project was funded by the DOST DOH AHEAD-

\section{REFERENCES}

1. World Bank. Philippine Health Sector Review: challenges and future directions. Washington, DC: World Bank; 2011.

2. Liu X, Zhu A, Tang S. Attraction and retention of rural primary health-care workers in the Asia Pacific Region. New Delhi: World Health Organization, Regional Office for South-East Asia. 2018.

3. University of the Philippines Manila College of Medicine (UPCM). Handbook on the UPCM return service obligation program and the regionalization program. Manila: UPCM; 2017.

4. Health Policy Development and Planning Bureau Department of Health. DOH Annual Report 2017. Manila: Department of Health; 2018.

5. Leonardia JA, Prytherch H, Ronquillo K, Nodora RG, Ruppel A. Assessment of factors influencing retention in the Philippine National Rural Physician Deployment Program. BMC Health Serv Res. 2012 Nov; 12:411. doi: 10.1186/1472-6963-12-411.

6. Gupta I, Joe W, Rudral S. Demand side financing in health: how far can it address the issue of low utilization in developing countries? 
World Health Report Background Paper no 27. Geneva: World Health Organization; 2010.

7. Bonilla-Chacin ME, Rathe M. UNICO: Demand side strategies for universal health coverage (UHC). World Hospitals and Health Services - Universal Health Coverage (UHC): Making progress towards the 2030 targets. 2018; 54(1):26-30.

8. Republic of the Philippines. Department of Budget and Management. National Budget Circular No. 572. Implementation of the Third Tranche Compensation Adjustment for Civilian Personnel in the National Government. January 3, 2018.

9. Ridic G, Gleason S, Ridic O. Comparisons of health care systems in the United States, Germany and Canada. Mater Sociomed. 2012; 24(2):112-20. doi: 10.5455/msm.2012.24.112-120.

10. Rudmik L, Wranik D, Rudisill-Michaelsen C. Physician payment methods: a focus on quality and cost control.J Otolaryngol Head Neck Surg. 2014; 43(1):34. doi: 10.1186/s40463-014-0034-6.

11. PhilHealth. The revised implementing rules and regulations of the National Health Insurance Act of 2013 (RA 7875 as amended by RA 9241 and 10606); 2013.

12. Chakraborty S. Philippines government sponsored health coverage program for poor households (English). Universal Health Coverage (UNICO) Studies Series No. 22. Washington, DC: World Bank; 2013.

13. Hussey P, Anderson GF. A comparison of single- and multi-payer health insurance systems and options for reform. Health Policy. 2003 Dec; 66(3):215-28. doi: 10.1016/s0168-8510(03)00050-2.

14. Romualdez AG, dela Rosa JFE, Flavier JDA, Quimbo SLA, HartiganGo KY, Lagrada LP, David LC. The Philippine health systems review. Geneva, Switzerland: World Health Organization; 2011.

15. Maresh OK. Part-time practice: making it work. Fam Pract Manag. 2004 Jun; 11(6):45-50.

16. American College of Physicians. Part time employment for physicians [Internet]. 2017 [cited 2019 Jan 6]. Available from: https://www. acponline.org/system/files/documents/running_practice/practice_ management/human_resources/part_time.pdf.

17. Darves B. Part-time physician practice on the rise. NEJM CareerCenter [Internet]. [cited 2019 Jan 5]. Available from: https:// www.nejmcareercenter.org/article/part-time-physician-practice-onthe-rise.

18. Carroll J. How doctors are paid now, and why it has to change. Manag Care. 2007 Dec; 16(12):22-6, 30.

19. Leigh JP, Tancredi D, Jerant A, Kravitz RL. Physician wages across specialties: informing the physician reimbursement debate. Arch Intern Med. 2010 Oct; 170(19):1728-34. doi: 10.1001/ archinternmed.2010.350.

20. Fessell D, Lexa FJ. High Relative Value Units and Unhappy. J Am Coll Radiol. 2017 Mar; 14(3):438-9. doi: 10.1016/j.jacr.2016.12.015.

21. Hauser SL, Johnston SC. That vexing problem of compensation. Ann Neurol. 2008 Jun; 63(6):A11-2. doi: 10.1002/ana.21431.

22. Brook RH. Physician compensation, cost, and quality. JAMA. 2010 Aug; 304(7):795-6. doi: 10.1001/jama.2010.1174.

23. Sarma S, Devlin RA, Hogg W. Physician's production of primary care in Ontario, Canada. Health Econ. 2010 Jan;19(1):14-30. doi: 10.1002/ hec.1447.

24. Gosden T, Sibbald B, Williams J, Petchey R, Leese B. Paying doctors by salary: a controlled study of general practitioner behaviour in England. Health Policy. 2003 Jun; 64(3):415-23. doi: 10.1016/s01688510(02)00204-x.
25. Kirsch M. Conflicts of interest and conflicting views on physician compensation: fee-for-service versus salaried medicine. Clin Gastroenterol Hepatol. 2010 Aug;8(8):666-8. doi: 10.1016/j.cgh. 2010.05.026.

26. Rudasingwa M, Uwizeye MR. Physicians' and nurses' attitudes towards performance-based financial incentives in Burundi: a qualitative study in the province of Gitega. Glob Health Action. 2017; 10(1):1270813. doi: 10.1080/16549716.2017.1270813.

27. Erus B, Hatipoglu O. Physician payment schemes and physician productivity: Analysis of Turkish healthcare reforms. Health Policy. 2017 May; 121(5):553-7. doi: 10.1016/j.healthpol.2017.02.012.

28. Karakolias S, Kastanioti C, Theodorou M, Polyzos N. Primary Care Doctors' Assessment of and Preferences on Their Remuneration. Inquiry. 2017 Jan;54:46958017692274. doi: 10.1177/ 0046958017692274

29. Baek JD, Xirasagar S, Stoskopf CH, Seidman RL. Physician-targeted financial incentives and primary care physicians' self-reported ability to provide high-quality primary care. J Prim Care Community Health. 2013 Jul; 4(3):182-8. doi: 10.1177/2150131912462036.

30. Gosden T, Williams J, Petchey R, Leese B, Sibbald B. Salaried contracts in UK general practice: a study of job satisfaction and stress. J Health Serv Res Policy. 2002 Jan; 7(1):26-33. doi: 10.1258/ 1355819021927647.

31. Spence D. The cause of clinical variance. BMJ. 2013 Feb; 346:f1122. doi: 10.1136/bmj.f1122.

32. Schnapp J. Doctor pay and social priorities. Mo Med. 2012 NovDec;109(6):435-6

33. Simon CJ, Emmons DW. Physician earnings at risk: an examination of capitated contracts. Health Aff (Millwood). 1997 May-Jun; 16(3):120-6.

34. Collier R. A clearer picture of physician income. CMAJ. 2013 Feb; 185(3):E143-4. doi: 10.1503/cmaj.109-4402.

35. Baerlocher MO, Noble J, Detsky AS. Impact of physician income source on productivity. Clin Invest Med. 2007; 30(1):42-3. doi: 10.25011/cim.v30i1.448.

36. Tilburt JC, Wynia MK, Sheeler RD, Thorsteinsdottir B, James KM, Egginton JS, et al. Views of US physicians about controlling health care costs. JAMA. 2013 Jul; 310(4):380-8. doi: 10.1001/ jama.2013.8278. Erratum in: JAMA. 2013 Aug 28;310(8):857.

37. Lochner J, Trowbridge E, Kamnetz S, Pandhi N. Family physician clinical compensation in an academic environment: moving away from the relative value unit. Fam Med. 2016 Jun; 48(6):459-66.

38. Sigsbee B. Physician compensation: approach and models in neurological practice. Neurol Clin. 2010 May;28(2):339-48. doi: 10.1016/j.ncl.2009.11.012.

39. Bailit MH, Burns ME, Dyer MB. Implementing value-based physician compensation: advice from early adopters. Healthc Financ Manage. $2015 \mathrm{Jul} ; 69(7): 40-7$.

40. Warren A, Karpinksi J, Topps M, Walker R, Carroll L. [Internet]. Moonlighting. 2016. CBD Policy Working Group Communique: Moonlighting. Royal College of Physicians and Surgeons of Canada. [cited 2020 Jan 18]. Available from: http://www.royalcollege. $\mathrm{ca} /$ rcsite/documents/cbd/cbd-policy-comm-moon-e.pdf 